\title{
Ten questions concerning thermal and indoor air quality effects on the performance of
} office work and schoolwork

\author{
Wargocki, Pawel; Wyon, David Peter
}

Published in:

Building and Environment

Link to article, DOI:

10.1016/j.buildenv.2016.11.020

Publication date:

2017

Document Version

Peer reviewed version

Link back to DTU Orbit

Citation $(A P A)$ :

Wargocki, P., \& Wyon, D. P. (2017). Ten questions concerning thermal and indoor air quality effects on the performance of office work and schoolwork. Building and Environment, 112, 359-366.

https://doi.org/10.1016/j.buildenv.2016.11.020

\section{General rights}

Copyright and moral rights for the publications made accessible in the public portal are retained by the authors and/or other copyright owners and it is a condition of accessing publications that users recognise and abide by the legal requirements associated with these rights.

- Users may download and print one copy of any publication from the public portal for the purpose of private study or research.

- You may not further distribute the material or use it for any profit-making activity or commercial gain

- You may freely distribute the URL identifying the publication in the public portal 


\title{
Ten questions concerning thermal and indoor air quality effects on the performance of office work and schoolwork
}

\author{
Pawel Wargocki and David P. Wyon \\ DTU-ICIEE, Technical University of Denmark
}

\begin{abstract}
Energy conservation in buildings as a way to reduce the emission of greenhouse gases is forcing an urgent re-examination of how closely thermal and air quality conditions should be controlled in buildings. Allowing either to depart even slightly from the optimum range would conserve very large amounts of energy and would in most cases have only marginal effects on health or subjective comfort. The question that then arises is whether occupant performance would be negatively affected and if so, by how much. This information is required for cost-benefit analyses. The answers in this paper are based on laboratory and field experiments that have been carried out since the massive increase in energy costs that took place in the 1970s. Although only a few of the mechanisms by which indoor environmental effects occur have been identified, it is already clear that any economies achieved by energy conservation will be greatly exceeded by the costs incurred due to decreased performance. Reducing emissions by allowing indoor environmental conditions to deteriorate would thus be so expensive that it would justify greatly increased investment in more efficient use of energy in buildings in which conditions are not allowed to deteriorate. Labour costs in buildings exceed energy costs by two orders of magnitude, and as even the thermal and air quality conditions that the majority of building occupants currently accept can be shown to reduce performance by $5-10 \%$ for adults and by $15-30 \%$ for children, we cannot afford to allow them to deteriorate still further.
\end{abstract}

\section{1) Do thermal conditions affect office work?}

It seems that the thermal state of the body, however achieved, is what affects arousal and thus performance: no difference in the performance of a whole battery of different tasks was found between two conditions of thermal neutrality with very different clothing insulation and air temperature: 0.6 clo at $23^{\circ} \mathrm{C}$ and $1.15 \mathrm{Clo}$ at $19^{\circ} \mathrm{C}$ (Wyon et al. 1975). In other words, thin clothing and warm air is equivalent to warm clothing and cool air, in terms of the resulting effect on both performance and thermal comfort.

Under moderately warm conditions, above neutrality, it is possible to avoid sweating by reducing metabolic heat production. This leads to a lowering of arousal, as people relax and generally try less hard to work fast. This is often a completely unconscious response to warmth. Aspects of mental performance with a low optimal level of arousal, such as memory (Wyon et al. 1979) and creative thinking (Wyon 1996a), are improved by exposure to a few degrees above thermal neutrality, but they too are impaired at higher temperatures, closer to and above the sweating threshold.

Tham and Willem (2010) showed that increased accuracy in the Tsai-Partington test indicates raised arousal, which improves concentration and would thus be expected to benefit rule-based logical thinking. They exposed heat acclimatised subjects living in the Tropics to 20,23 and $26^{\circ} \mathrm{C}$ and observed higher arousal at $20^{\circ} \mathrm{C}$, as indicated by measurements of stress biomarkers in saliva. Activation of the sympathetic nervous system and higher alertness are beneficial for tasks that require attention and the ability to sustain prolonged mental effort.

Individual control of the thermal environment may be necessary if optimal performance of office work is to be achieved. Wyon (1996b) showed that individual control equivalent to $\pm 3^{\circ} \mathrm{K}$ would be 
expected to improve the performance of mental tasks requiring concentration by $2.7 \%$. A decrease of this magnitude $(2.8 \%)$ in the rate of claims-processing in an insurance office had been demonstrated by Kroner et al. (1992) when individual microclimate control devices in an insurance office were temporarily disabled. Wyon showed that this degree of individual control $\left( \pm 3^{\circ} \mathrm{K}\right)$ would be expected to improve the group mean performance of routine office tasks by $7 \%$.

Figure 1 shows the magnitude of the effects of temperature on performance that have been documented in the literature. Figure 2 shows an experimental relationship between thermal discomfort and the performance of office work.

Fig. 1 The relationship between temperature and the performance of office work that was derived by Seppänen et al. (2006a) from a review of the literature.

Fig. 2 The experimental relationship between thermal discomfort due to heat and the performance of office work according to Lan et al. (2011b)

\section{2) Do thermal conditions affect schoolwork?}

A comprehensive set of experiments on the effects of classroom temperatures on the performance of schoolwork was carried out in Sweden (Wyon, 1970). In these experiments, three parallel classes of 9-10-year-old children were exposed for two hours to each of three classroom temperatures: 20, 27 and $30^{\circ} \mathrm{C}$, encountered in balanced order, and four classes of 11-12-year-old children were similarly exposed to 20 and $30^{\circ} \mathrm{C}$ in the morning and the afternoon in a $2 \times 2$ design, again in balanced order of presentation of conditions (Holmberg and Wyon, 1969). The temperatures were artificially raised in these experiments. The children performed a number of school exercises, including numerical tasks (addition, multiplication, number-checking) and language-based tasks (reading and comprehension, supplying synonyms and antonyms) so that their rate of working and the number of errors they made could be quantified. The children's performance of both types of task was significantly lower at 27 and $30^{\circ} \mathrm{C}$ in comparison with $20^{\circ} \mathrm{C}$. In the numerical tasks, the effect was on rate of working, but both reading comprehension and reading speed were reduced by raised temperatures. Performance tended to be lower, though not significantly lower, at 27 than at $30^{\circ} \mathrm{C}$, and the negative effects of raised classroom temperatures were significant in the afternoon, when the children were fatigued, but not in the morning. The magnitude of the negative effect of temperature on performance was for some tasks as great as $30 \%$.

Field intervention experiments were carried out in elementary school classrooms in late summer by Wargocki and Wyon $(2007 \mathrm{a}, \mathrm{b})$. In these experiments, the air temperature was reduced to about $20^{\circ} \mathrm{C}$ by operating split cooling units that had been installed in the classrooms for the purpose of the experiments. In the first experiment, the average air temperature in the classrooms was about $20^{\circ} \mathrm{C}$ when cooling was provided and $23.6^{\circ} \mathrm{C}$ in the uncontrolled reference condition, so that the difference was $3.6^{\circ} \mathrm{K}$. In the second experiment, with different children in the same two classrooms the following summer, the air temperature in the classrooms was $21.6^{\circ} \mathrm{C}$ when cooling was provided and $24.9^{\circ} \mathrm{C}$ in the reference condition, i.e. a $3.3^{\circ} \mathrm{K}$ difference. The classrooms in which the experiments were conducted were all mechanically ventilated with $100 \%$ outdoor air. The interventions were implemented in a crossover design that was balanced for order of presentation: each experiment was carried out in two parallel classrooms at a time and each condition lasted for a week. In alternate weeks, the improved condition was imposed in one classroom, the other classroom acting as the reference condition during that week, and the conditions were then switched between the classrooms for the following week. The children acted as their own controls, so any observed dif- 
ferences in performance between conditions cannot have been due to differences between groups of children. Both teachers and pupils were blind to interventions. During the experiments, the teachers and pupils were allowed to open the windows and doors as usual and the teaching environment and daily routines were as normal. During each week the children performed tasks resembling typical schoolwork: addition, multiplication, subtraction, number comparison, logical thinking (i.e. grammatical reasoning), reading and comprehension, proof-reading against dictation. The duration of the tasks was short enough to ensure that children could not normally complete them in the time available. Up to 10 minutes was allocated for each task. When the temperature was reduced to $20^{\circ} \mathrm{C}$, the performance of 2 arithmetical and 2 language-based tests improved significantly, as had been reported by Holmberg and Wyon (1969 op. cit.). This time the improvement was always in terms of speed of performance, not accuracy. The average magnitude of the effects as a function of temperature is shown in Figure 3.

Sarbu and Pacurar (2015) examined the performance of 18 university students in a classroom over a period of 36 days. The classroom temperatures were manipulated by operating or idling the air cooling and changing the air cooling set-point; they remained between 22 and $29^{\circ} \mathrm{C}$. The students repeatedly performed two attention tests: the concentrated attention test (Kraepelin test) and the distributive attention test (Prague test). These tests took 10 minutes and 7 minutes to complete, respectively. The results showed that the performance of students on both tests followed an invertedU curve, similarly to what was observed for the effects of temperature on the performance of office work by adults (Seppänen et al., 2006a; Lan et al., 2011b) and in the earlier experiments of Wyon (1969). The temperatures for optimal performance in each test were different: higher (about $27-28^{\circ} \mathrm{C}$ ) for the Prague test and lower (about $25-26^{\circ} \mathrm{C}$ ) for the Kraepelin test, exactly as would be expected if the change in performance followed the psychological theory of arousal - moderately higher temperatures reduce the arousal/stress level and are thus beneficial for tests requiring high cue-utilisation, as is the case for the Prague test.

Haverinen-Shaughnessy and Shaughnessy (2015) measured temperatures in 140 fifth-grade classrooms in 70 elementary schools for a week-long period and correlated them with a state-wide assessment of learning. Average indoor temperature was $23^{\circ} \mathrm{C}$ and it varied between about $20^{\circ} \mathrm{C}$ and $25^{\circ} \mathrm{C}$. Modelling showed that there was a 12-13 point increase in mathematics score for each 1 degree decrease of temperature (0.5\%/degree). Park (2016) analysed more than 4.5 million schoolleaving examination results from New York City high schools and found that taking the examination on a day when the ambient temperature was $32^{\circ} \mathrm{C}$ increased the risk of failing to pass by $12.3 \%$ compared with the results obtained when the examination was taken on a day when the ambient temperature was $22^{\circ} \mathrm{C}$. He showed additionally that an increase in temperature of $1^{\circ} \mathrm{C}$ will reduce the examination score by $0.4 \%$ which is quite similar to what Haverinen-Shaughnessy and Shaugnessy (2015 op.cit) observed in their study. He also showed an effect on learning, as an increased number of hot days (above $27^{\circ} \mathrm{C}$ ) during the school-year prior to taking the school-leaving examination had a negative effect on the results obtained in the examination.

Fig. 3 The experimental relationship between classroom temperature and the performance of schoolwork that was found by Wargocki and Wyon (2006)

\section{3) How do thermal conditions affect performance?}

Thermal conditions can affect the performance of office work by at least 6 different mechanisms (Wyon, 1996c): (i) Thermal discomfort distracts attention; (ii) Warmth lowers arousal (the state of activation of an individual) (Provins, 1966; Willem, 2006), exacerbates building-related symptoms 
and has a negative effect on cognition (Wyon, 1974; Lan et al., 2011a); (iii) Cold conditions decrease finger temperatures and thus have a negative effect on manual dexterity (Meese at al. 1982); (iv) Rapid temperature swings have the same effects on office work as slightly raised room temperatures (Wyon, 1979); (v) Vertical thermal gradients reduce perceived air quality at head height and so lead to a reduction in room temperature that then causes complaints of cold at floor level that are due to vasoconstriction, not to the low temperatures at floor level (Wyon and Sandberg 1996); and (vi) Raised temperatures can result in increased carbon dioxide (CO2) concentration in the blood, which may cause headaches (Lan et al., 2011a).

In interpreting experiments on thermal and air quality effects on office work and schoolwork, it should be assumed that thermal discomfort sensations due to cold or heat stress distract attention, and that the physiological responses to heat stress reduce arousal and therefore motivation to exert effort. More generally, the effects of thermal conditions appear to be mediated directly by the physiological changes that take place, including vasoconstriction in the cold, which reduces manual dexterity, and an increase in the blood gas level of $\mathrm{CO} 2$ in response to heat, which causes headache and increased difficulty in thinking clearly. These suggested mechanisms are depicted as a diagram in Figure 4.

Hancock and Vasmatzidis (1998) suggested that a zone of psychological and physiological adaptability exists, in which people can tolerate thermal stress and within which there will be no effects on cognitive performance. However, as indicated by the study of Lan et al. (2011a), increasing temperatures and the physiological responses that then occur, including an increase in the blood gas concentration of $\mathrm{CO} 2$, result in a range of negative health symptoms such as headaches or difficulty in concentrating and thinking clearly that can reasonably be expected to have direct negative effects on cognitive performance unless more effort is exerted to counteract them. Tanabe et al. (2007) showed that exerting more effort in this way is only possible for a limited time, so in stipulating the thermal conditions in which adults or children will have to work all day and every day, it should not be assumed that extra effort will always be exerted to counteract the physiologically adaptive decrease in arousal and motivation that occurs in warm conditions (as a way of decreasing metabolic rate and thus the heat that must be lost to the indoor environment). The Adaptive Thermal Comfort model (de Dear and Brager 2001) assumes that this behavioural and physiological response to warmth will take place if adjustments in clothing insulation and air velocity prove inadequate, and that this will increase "thermal acceptability". Although this is true, it has been shown above that it will be at the cost of a substantial decrease in the performance of both office work and schoolwork.

Fig. 4 The mechanisms by which mental work is affected by the thermal environment.

\section{4) Does subjective acceptance imply optimal performance?}

As perceived thermal discomfort almost inevitably accompanies the physiological changes that occur in response to thermal conditions that deviate from thermal neutrality, it has not yet been possible to determine whether subjective acceptance of thermal discomfort would be sufficient to remove the direct effects of physiological responses on performance, although this seems unlikely.

\section{5) Does indoor air quality affect office work?}

A series of experiments by Wargocki et al. (1999; 2000b; 2002), summarised by Wyon (2004), examined the effects of indoor air quality on the cognitive skills that are essential for office work. In 
an intervention experiment, Wargocki et al. (1999 op. cit.) altered the indoor air quality in a normal office while the health, comfort and performance of the occupants were measured. Indoor air quality was altered by decreasing the pollution load, i.e. by physically removing a hidden pollution source without informing the subjects, while maintaining an outdoor air supply rate of $10 \mathrm{~L} / \mathrm{s} \mathrm{per}$ person. The major pollution source was a carpet that had been used for 20 years in an office and was present behind a partition in a quantity corresponding to the floor area of the office in which the exposures took place, although low background emissions and the bioeffluents emitted by the subjects themselves were always present. Thirty subjects performed different cognitive tests and typing and addition tasks to simulate typical office work throughout 4.5 hour exposures. The indoor air quality caused $70 \%$ to be dissatisfied with the air quality when the used carpet was present and $25 \%$ when it was absent. The presence of the used carpet caused subjects to type $6.5 \%$ more slowly, to make $18 \%$ more typing errors, and to experience more headache.

Lagercrantz et al. (2000) replicated the study of Wargocki et al. (1999 op. cit.) with a different group of subjects and the same carpet. This time the resulting indoor air quality caused $60 \%$ of the subjects to report that they were dissatisfied with the air quality when the carpet was present and $40 \%$ to be dissatisfied when the carpet was absent. The subjects typed $1.5 \%$ more slowly and made $15 \%$ more errors in an addition task. Meta-analysis of the two studies by Wargocki et al. (2002) confirmed that their results are compatible.

The original study of Wargocki et al. (1999) was repeated in the same office by Bakó-Biró et al. (2004) with a different pollution source. Instead of carpet, they used 6 Personal Computers (PCs) with Cathode Ray Tube Visual Display Units (CRT/VDU) that had been in operation for about 500 h, corresponding to approximately 3 months of normal office use. $40 \%$ of the subjects reported that they were dissatisfied with the air quality when the PCs were present behind the screen, while only $10 \%$ were dissatisfied when the PCs were absent. Although the differences between conditions in terms of typing speed were small, more subjects typed slowly and all subjects made more typing errors when the PCs were present. Proofreading was affected negatively but not significantly. Combining the observed effects on the speed and accuracy of typing and the decrease in speed of proofreading, it could be shown that overall text-processing would be performed $9 \%$ more slowly if PCs were present, thus validating the findings of Wargocki et al. (1999) with a very different source of pollution.

Indoor air quality can also be modified by changing the ventilation rate. Wargocki et al. (2000a) increased the outdoor air supply rate from 3 to 10 or to $30 \mathrm{~L} / \mathrm{s}$ per person with the original pollution source, a used carpet, always present behind the partition. $60 \%$ were dissatisfied with the resulting indoor air quality at the lowest ventilation rate and 30\% were dissatisfied at the highest rate. By integrating speed and accuracy into an overall measure it was possible to show that the performance of the text-typing task improved by about $1 \%$ for every two-fold increase in the outdoor air supply rate. The performance of the addition and proofreading tasks followed the same trend, but the effects did not reach significance. In an open-ended test of creative thinking, subjects provided 10\% more answers and more original answers at $10 \mathrm{~L} / \mathrm{s}$ per person than at $3 \mathrm{~L} / \mathrm{s}$ per person. As stress (raised level of arousal) is inimical to creative thinking (see Answer 1 above), this result is in accordance with the more recent finding by Zhang et al.(2016a) that poor air quality has the physiological effect of increasing arousal.

In another study in which the outdoor air supply rate was changed, Park and Yoon (2011) showed improved performance of typing, addition and memorisation by on average $2.5 \%$ to $5 \%$, when ventilation rates were changed between 5,10 and $20 \mathrm{~L} / \mathrm{s}$ per person. In their experiments, the main pol- 
lutants were volatile organic compounds emitted from the new finishing materials that were present in the chamber where the experiments were carried out.

Field intervention studies confirm these laboratory findings. Wargocki et al. (2004) showed that the performance of call-centre operators in Denmark improved by $6 \%$ when the outdoor air supply rate was increased from 2.5 to $25 \mathrm{~L} / \mathrm{s}$ per person, but only when new bag filters had been installed in the ventilation system; with used bag filters an increase in the ventilation rate reduced measured performance by $8 \%$.

In a study by Federspiel et al. (2004), the performance of call-centre operators in California improved by $2 \%$ when the outdoor air supply rate was increased from 8 to $94 \mathrm{~L} / \mathrm{s}$ per person, although an increase from 8 to 20 or $53 \mathrm{~L} / \mathrm{s}$ per person reduced their performance, probably because used bag filters were in place.

Tham et al. (2003) showed that the performance of call-centre operators in Singapore improved by $9 \%$ when the outdoor air supply rate was increased from 10 to $23 \mathrm{~L} / \mathrm{s}$ per person in an office building with no bag filters (electrostatic filters were being used instead). Call-centres were selected for field experiments, as in the two studies mentioned above by Federspiel et al. and Wargocki et al. because the operators perform high-level office work, dealing directly with customers and thus having to solve unexpected problems under time pressure. Their work requires concentration, verbal communication, logical thinking under time pressure, visual attention and very often the use of sophisticated computer software. These skills are common to most office tasks, so if call-centre performance is affected by changes in the indoor environment, other office tasks are likely to be similarly affected. In fact, talk-time is a conservative indicator of performance, because when talk-time is reduced, it seems likely that operators had been able to provide an increased quality of service, because it is reasonable to assume that customers dissatisfied with the quality of service would be likely to prolong the call in order to achieve their goal.

Figure 5 shows the average magnitude of the effects of the outdoor air supply rate (a proxy for indoor air quality) on the performance of office work that has been reported in the literature.

Fig. 5 The relationship between the outdoor air supply rate per person and the performance of office work that was derived by Seppänen et al. (2006b) from a review of the literature.

\section{6) Does indoor air quality affect schoolwork?}

Wargocki and Wyon (2007a,b) carried out three field intervention experiments in school classrooms in Denmark in which the outdoor air supply rate per person was increased from about 3 to $9.5 \mathrm{~L} / \mathrm{s}$ per person using the existing mechanical ventilation system (by increasing the fan capacity and rebalancing the system to direct more outdoor air to first one and then the other of the two classrooms in which performance was being measured). The children's usual teachers administered parallel versions of language-based and numerical performance tasks representing different aspects of schoolwork, from reading to mathematics. When the outdoor air supply rate increased, the speed at which the children performed 4 numerical and 2 language-based tasks improved significantly, and in the case of one numerical task the percentage of errors was significantly reduced. It could be shown that doubling the outdoor air supply rate would improve the performance of schoolwork in terms of speed by about $8 \%$ overall, and by $14 \%$ for the tasks that were affected significantly, with only a negligible effect on errors (Figure 6). A similar experiment by Petersen et al. (2015) in Denmark obtained very similar results. In a field intervention study in classrooms in England (Bakó- 
Biró et al., 2007), the time needed to solve simple mathematics tests was significantly reduced when the ventilation rate was increased from below 0.5 to $13-16 \mathrm{~L} / \mathrm{s}$ per person.

Cross-sectional surveys in large numbers of schools have confirmed these experimental findings: Haverinen-Shaughnessy et al. (2011) measured CO2 levels in 100 fifth grade classrooms in 100 schools in the USA and showed that poor ventilation reduced the number of pupils managing to pass language and mathematics tests. A linear relationship was found suggesting 3\% more pupils passed the tests for every $1 \mathrm{~L} / \mathrm{s}$ per person increase in ventilation up to $7 \mathrm{~L} / \mathrm{s}$ per person. In another study in 140 fifth grade classrooms in 70 schools in the USA, Haverinen-Shaughnessy and Shaughnessy (2015) showed that mathematics scores improved by about $0.5 \%$ for every $1 \mathrm{~L} / \mathrm{s}$ per person increase in ventilation rate in the range from 0.9 to $7 \mathrm{~L} / \mathrm{s}$ per person.

Fig. 6 The experimental relationship between outdoor air supply rate per child and classroom performance of schoolwork that was found by Wargocki and Wyon (2006)

\section{7) How does indoor air quality affect performance?}

The mechanisms suggested below are shown in Figure 7. They are similar to the mechanisms suggested for effects of thermal discomfort and shown in Figure 4.

Among the thousands of pollutants routinely present at low concentrations in indoor air, those affecting performance at these low concentrations have not yet been identified, although toluene and a mixture of 22 of the Volatile Organic Compounds (VOCs) that are usually present indoors have been shown to affect cognitive performance at much high concentrations (Baelum et al, 1985; Mølhave et al., 1986).

There is some evidence that gas-phase pollutants rather than airborne particulates are to blame for negative short-term effects (leaving aside any long-term negative effects of particulates on health): Wargocki et al. (2008) installed electrostatic air cleaners in 6 classrooms in 3 schools in Sweden in winter and early spring. The classrooms were mechanically ventilated with $100 \%$ outdoor air. The interventions were implemented in a crossover design in parallel classrooms. The electrostatic air cleaners had their intended effect on airborne particle concentrations, which in all size ranges were substantially reduced by operating the air cleaners, and settled dust on horizontal surfaces was measurably reduced, but this had no beneficial effect on the performance of the wide range of tasks selected to be characteristic of schoolwork, which included the language-based and mathematics tasks used by Wargocki and Wyon (2007a). Since in those experiments increasing outdoor air supply rate did improve performance, it was inferred that the observed effects should be attributed to the dilution and removal of gaseous pollutants.

Among gaseous pollutants, it is not only the bioeffluents emitted by occupants that have negative effects on performance, but also the emissions from the materials present in buildings. Among the bioeffluents, $\mathrm{CO} 2$, long regarded as a convenient indicator of the changing concentration of all bioeffluents, has now been shown to have some negative effects, although they have proved to be reproducible only on the performance of tasks that require complex decision-making under time pressure. Kajtár and Herczeg (2012) reported a decrease in the performance of a proof-reading task during exposure to $\mathrm{CO} 2$ at 3,000 ppm, but only in one of several exposures. Experiments by Satish et al. (2012) exposing subjects for 2.5 hours to $\mathrm{CO} 2$ levels that had been raised by releasing chemically pure CO2 and by Allen et al. (2015), who exposed subjects similarly for an entire working day, then demonstrated conclusively that exposures to $\mathrm{CO} 2$ at levels as low as 1,000 ppm 
systematically reduced the performance of a battery of tests known as Strategic Management Simulation (SMS) (Streufert et al., 1988), which examines the higher-order cognitive skills exercised by top management or by military leaders by exposing participants to complex, unfamiliar and therefore stressful situations that reproduce the real-world challenges endured by top decision-makers, including information overload and time stress. Subsequent experiments by Zhang et al. $(2016 \mathrm{a}, \mathrm{b}, \mathrm{c})$ could not confirm that $\mathrm{CO} 2$ had any effect on the performance of more routine kinds of work, nor could they detect any physiological effects of exposure to $\mathrm{CO} 2$ up to $\mathrm{CO} 2$ concentrations of 4,900 ppm, which is close to the 8-hour occupational exposure limit. The discrepancy may be due to the level of stress imposed by the tests themselves: it seems possible that the complexity and the time pressure of SMS created a physiological state in which performance became sensitive to $\mathrm{CO} 2$. Levels of task difficulty must therefore be considered as an important additional variable to be taken into account when any of the effects of the indoor environment on cognitive performance are examined.

Poor indoor air quality can also be regarded as reducing performance if it increases sickness absence, as no work can be performed by absent workers: Milton et al. (2000) showed that the risk of short-term sick leave associated with respiratory diseases caused by infection was significantly higher in offices in the USA with an outdoor air supply rate of $12 \mathrm{~L} / \mathrm{s}$ per person compared to other offices ventilated with $24 \mathrm{~L} / \mathrm{s}$ per person. Simons et al. (2010) found high student absenteeism to be associated with poor ventilation in 2,751 New York schools. Shendell et al. (2004) found student absence decreased by $10-20 \%$ when the CO2 concentration decreased by 1,000 ppm in 434 American classrooms. A study by Gaihre et al. (2014) in Scottish schools showed that an increase of $100 \mathrm{ppm}$ of $\mathrm{CO} 2$ corresponded to a $0.2 \%$ increase in absence rates (roughly one order of magnitude lower than the data of Shendell et al. (2004 op. cit.), and corresponding to about to 0.5 day a year in the 190 days of a school year. In another very comprehensive study in 162 Californian classrooms, Mendell et al. (2013) observed that sickness absence decreased by as much as $1.6 \%$ for each additional $1 \mathrm{~L} / \mathrm{s}$ per person of ventilation rate. This is a smaller effect than occurred in the data of Shendell et al. (2004 op. cit.) but much higher than in the data of Gaihre et al. (op.cit.). Fisk et al. (2003) derived a relationship between sick-leave and ventilation rate that predicts a $10 \%$ reduction in illness or sick leave when the outdoor air supply rate is doubled.

Poor indoor air quality at home may reduce next-day performance at work or at school by decreasing sleep quality or duration: in identical corridor rooms, 16 students slept with high or low rates of outdoor air supply that were achieved by operating or idling a simple fan mounted in the air-intake aperture (Strøm-Tejsen et al., 2016). The resulting average CO2 levels were about 850 ppm and 2,400 ppm, respectively. The subjects reported that the air in their room seemed to be more fresh, that they felt more refreshed and that their mental state was better in the condition in which the fan was operated. The objectively measured sleep efficiency (time spent asleep) was higher and their task performance the following morning was better when the fan had been operated. These results are supported and extended by those of a subsequent study in China which showed that elderly subjects sleeping with a fresh air supply outlet device directed towards the head had a shorter sleep onset latency, measured objectively, and that their heart rate variability was reduced (Zhou et al., 2014).

Fig. 7 The mechanisms by which mental performance is affected by air quality

\section{8) Does subjective acceptance of poor air quality imply optimal performance?}


In the field intervention experiments in which the indoor air quality was covertly changed (Wargocki et al. 2004), no complaints related to air quality were received even though inadvertent changes in air temperature of as little as $0.5^{\circ} \mathrm{K}$ led to immediate protests, so as the observed effects on performance cannot therefore have been due to the distraction of dissatisfaction with the air quality, they must have been due to the physiological effects caused by poor air quality, among which a slight increase in the blood gas concentration of $\mathrm{CO} 2$, causing headache and increased difficulty in thinking clearly, seems the most likely mechanism, as suggested by Bakó-Biró et al. (2005).

\section{9) Is self-estimated performance an indicator of objectively measured performance?}

As an increasing number of studies that assume this to be the case are being performed, it is important to recall a unique and well-executed field experiment in which self-estimates and objective measures of individual performance were both measured before and after an insurance company moved to new and purportedly better premises in New York (Kroner et al., 1992): selfestimates of performance showed no change in the period immediately following the move, presumably because none was expected or perceived, while objective measures showed a 30\% decrease in the rate at which insurance claims were being resolved in this period. In experiments in Japan that were performed by Murakami et al. (2006) and duplicated by Ito et al. (2006), in which both thermal and air quality conditions deteriorated or improved at the same time, self-estimated performance underestimated the magnitude of the effect on objectively measured performance in the former experiment but overestimated it in the latter experiment.

\section{0) How should real-world effects on performance be predicted?}

Well-controlled climate-chamber experiments are essential for determining cause and effect and for identifying the mechanisms involved, but as real work is not performed in climate chambers, the performance of simulated work, or of tests designed to be sensitive to environmental effects, is what is measured there. It not difficult to devise tests that are extremely sensitive to any given environmental effect, be it of noise, lighting, temperature, humidity, air velocity or air quality, but this does not mean that real work will be affected to the same extent, or at all. The performance of simulated work by paid subjects should never be assumed to predict the existence of real-world effects, still less their magnitude, unless the findings have been validated in field intervention experiments in which the performance of real work is monitored quantitatively. Some examples of this kind of field validation are described in the present paper, but they are rarely undertaken because of the difficulty of measuring day-to-day performance in real workplaces. As noted above, effects on self-estimated performance may be due to expectation so they do not constitute validation.

\section{Conclusions}

- It is well documented that both thermal conditions and indoor air quality do affect the performance of office work and schoolwork.

- The mechanisms that mediate the effects of thermal conditions and indoor air quality on performance are surprisingly similar.

- Thermal conditions and indoor air quality tend to affect performance "across the board", suggesting that it is the ability to concentrate and to think clearly that is affected, as this is common to all aspects of mental performance.

- It is not proven that subjective acceptance of indoor environmental conditions leads to 
optimal performance.

- Self-estimated performance is not an indicator of objectively measured performance.

- Motivation to perform well may itself be influenced by the indoor environment.

- Performance tests, however environmentally sensitive, may not in fact predict the performance of real work.

- The results obtained in laboratory experiments using paid subjects, simulated work and limited exposure times must be validated in field intervention experiments in which the performance of real work is monitored over time in normally functioning offices and schools.

\section{REFERENCES}

Allen, J., Macnaughton, P., Satish, U., Santanam, S., Vallarino, J. and Spengler, J. (2015). Associations of cognitive function scores with carbon dioxide, ventilation, and volatile organic compound exposures in office workers: a controlled exposure study of green and conventional office environments. Environmental Health Perspectives, 124(6), pp.805-812.

Bakó-Biró, Z., Wargocki, P. Weschler, C. and Fanger, P. (2004). Effects of pollution from personal computers on perceived air quality, SBS symptoms and productivity in offices. Indoor Air, 14, pp. 178-187.

Bakó-Biró, Z., Wargocki, P., Wyon, D. and Fanger, P. (2005). Indoor air quality effects on $\mathrm{CO}_{2}$ levels in exhaled air during office work. In: Proceedings of Indoor Air 2005, Beijing, China, 1(1), pp.76-80.

Bakó-Biró, Z., Kochhar, N., Clements-Croome, D., Awbi, H. and Williams, M. (2007). Ventilation rates in schools and learning performance. In: Proceedings of CLIMA 2007, Helsinki, Finland: FINVAC, pp.1434-1440.

Bælum, J., Andersen, I., Lundqvist, G., Mølhave, L., Pedersen, O., Væth, M. and Wyon, D. (1985). Response of solvent exposed printers and unexposed controls to six-hour toluene exposure. Scandinavian Journal of Work, Environment \& Health, 11, pp.271-280.

deDear, R. and Brager, G. (2001). The adaptive model of thermal comfort and energy conservation in the built environment. International Journal of Biometeorology, 45, pp.100-108

Federspiel, C., Fisk, W., Price, P., Liu, G., Faulkner, D., Dibartolemeo, D., Sullivan, D. and Lahiff. M. (2004). Worker performance and ventilation in a call-center: analyses of work performance data for registered nurses. Indoor Air, 14(s8), pp.41-50

Fisk, W., Seppänen, O., Faulkner, D. and Huang, J. (2003). Cost benefit analysis of ventilation control strategies in an office building, In: Proceedings of Healthy Buildings 2003, Singapore: NUS, 3, pp.361-366

Gaihre, S., Semple, S., Miller, J., Fielding, S. and Turner, S. (2014). Classroom carbon dioxide concentration, school attendance, and educational attainment. Journal of School Health, 849, pp.

569-574. 
Hancock, P. and Vasmatzidis, I. (1998). Human occupational and performance limits under stress: the thermal environment as a prototypical example. Ergonomics, 41(8), pp.1169-1191.

Haverinen-Shaughnessy, U., Moschandreas, D. and Shaughnessy, R. (2011). Association between substandard classroom ventilation rates and students' academic achievement. Indoor Air, 212, pp. 121-131.

Haverinen-Shaughnessy, U. and Shaughnessy, R. (2015). Effects of classroom ventilation rate and temperature on students' test scores. PloS One, 10(8), e0136165. (doi: 10.1371/journal.pone. 0136165)

Holmberg, I. and Wyon, D. (1969). The dependence of performance in school on classroom temperature. Educational \& Psychological Interactions, 31, 20p. Malmö, Sweden: School of Education.

Ito, K., Murakami, D, Kaneko, T. and Fukao, H. (2006). Study on the productivity in classroom Part 2. Realistic simulation experiment on effects of air quality /thermal environment on learning performance. In: Proceedings of Healthy Buildings 2006, Lisbon, Portugal: ISIAQ, pp.207-212.

Kajtár, L. and Herczeg, L. (2012). Influence of carbon-dioxide concentration on human well-being and intensity of mental work. QJ Hung Meteorol Serv, 116, pp.145-69.

Kroner, W., Stark-Martin, J. and Willemain, T. (1992). Using advanced office technology to increase productivity: the impact of environmentally responsive workstations ERWs. on productivity and worker attitude. Troy, NY, USA: Rensselaer Polytechnic Institute, Center for Architectural Research.

Lagercrantz, L., Wistrand, M., Willén, U., Wargocki, P., Witterseh, T. and Sundell, J. (2000). Negative impact of air pollution on productivity: Previous Danish findings repeated in new Swedish test room, In: Proceeding of Healthy Buildings 2000, Espoo, Finland: ISIAQ, 1, pp.653-658.

Lan, L., Wargocki, P., Wyon, D. and Lian, Z. (2011a). Effects of thermal discomfort in an office on perceived air quality, SBS symptoms, physiological responses, and human performance. Indoor Air, 21(5), pp.376-390. (DOI: 10.1111/j.1600-0668.2011.00714.x)

Lan, L., Wargocki, P. and Lian, Z. (2011b). Quantitative measurement of productivity loss due to thermal discomfort. Energy and Buildings, 435, pp.1057-1062.

Meese, G., Kok, R., Lewis, M. and Wyon, D. (1982). Effects of moderate cold and heat stress on factory workers in Southern Africa, 2: skill and performance in the cold. South African J Science, 78, pp.189-197.

Mendell, M., Eliseeva, E., Davies, M., Spears, M., Lobscheid, A., Fisk, W. and Apte, M. (2013). Association of classroom ventilation with reduced illness absence: a prospective study in California elementary schools. Indoor Air, 236, pp.515-528.

Milton, D., Glencross, P. and Walters, M. (2000). Risk of sick-leave associated with outdoor air supply rate, humidification and occupants complaints. Indoor Air, 10, pp.212-221.

Murakami, S., Kaneko, T, Ito, K. and Fukao, H. (2006). Study on the Productivity in Classroom Part 1. Field Survey on Effects of Air Quality/Thermal Environment on Learning Performance. In: Proceedings of Healthy Buildings 2006, Lisbon, Portugal: ISIAQ, pp.271-276.

Mølhave, L., Bach, B. and Pedersen, O. (1986). Human reactions to low concentrations of volatile 
organic compounds. Environment International, 12, pp.167-175.

Park, J. (2016) Temperature, test scores, and educational attainment. Report from the Harvard University Economics Department.

Park, J. and Yoon, C. (2011). The effects of outdoor air supply rate on work performance during 8-h work period. Indoor Air, 21(4), pp.284-290.

Petersen, S., Jensen, K., Pedersen, A. and Rasmussen, H. (2016). The effect of increased classroom ventilation rate indicated by reduced $\mathrm{CO} 2$ concentration on the performance of schoolwork by children. Indoor Air, 26(3), pp.366-379. (DOI: 10.1111/ina.12210).

Provins, K. (1966). Environmental heat, body temperature and behavior: an hypothesis. Australian J Psychology, 18, pp.118-129.

Sarbu, I. and Pacurar, C. (2015). Experimental and numerical research to assess indoor environment quality and schoolwork performance in university classrooms. Building and Environment. 93, pp. 141-154.

Satish, U., Mendell, M., Shekhar, K., Hotchi, T., Sullivan, D., Streufert, S. and Fisk, W. (2012). Is $\mathrm{CO} 2$ an indoor pollutant? Direct effects of low-to-moderate $\mathrm{CO} 2$ concentrations on human decision-making performance. Environmental Health Perspectives, 120(12), pp.1671-1671. (DOI: 10.1289/ehp.1104789)

Seppänen, O., Fisk, W. and Lei, Q. (2006a). Effect of temperature on task performance in office environment. In: Proceedings of Cold Climate HVAC conference, Moscow

Seppänen, O. Fisk, W. and Lei, Q. (2006b). Ventilation and performance in office work. Indoor Air, 16 , pp.28-35

Shendell, D., Prill, R., Fisk, W., Apte, M., Blake, D. and Faulkner, D. (2004). Associations between classroom CO2 concentrations and student attendance in Washington and Idaho. Indoor Air, 145, pp.333-341.

Simons, E., Hwang, S., Fitzgerald, E., Kielb, C. and Lin, S. (2010). The impact of school building conditions on student absenteeism in upstate New York. American J of Public Health, 1009, pp. 1679-1686.

Streufert, S., Pogash, R. and Piasecki, M. (1988). Simulation-based assessment of managerial competence: reliability and validity. Personnel Psychology, 41(3), pp.537-557.

Strøm-Tejsen, P., Zukowska, D., Wargocki, P. and Wyon, D. (2015). The effects of bedroom air quality on sleep and next-day performance. Indoor Air, 26, pp.679-686. (DOI: 10.1111/ina.12254), pp.1-8.

Tanabe, S., Nishihara, N. and Haneda, M. (2007). Indoor temperature, productivity, and fatigue in office tasks. HVAC\&R Research, 134, pp.623-633.

Tham, K. and Willem, H. (2010). Room air temperature affects occupants' physiology, perceptions and mental alertness. Building and Environment, 451, pp.40-44. 
Tham, K., Willem, H., Sekhar, S., Wyon, D., Wargocki, P. and Fanger, P. (2003). Temperature and ventilation effects on the work performance of office workers (study of a call center in the tropics), In: Proceedings of Healthy Buildings 2003, 3, pp.280-286.

Willem H. (2006). Thermal and indoor air quality effects on physiological responses, perception and performance of tropically acclimatized people, Ph.D. Thesis, National University of Singapore.

Wargocki, P., Wyon, D., Baik, Y., Clausen, G. and Fanger, P. (1999). Perceived air quality, Sick Building Syndrome SBS. symptoms and productivity in an office with two different pollution loads. Indoor Air, 9, pp.165-179.

Wargocki, P., Wyon, D. and Fanger, P. (2000a). Productivity is affected by the air quality in offices. In: Proceeding of Healthy Buildings 2000, Espoo, Finland: ISIAQ, 1, pp.635-640.

Wargocki, P., Wyon, D., Sundell, J., Clausen, G. and Fanger P. (2000b). The effects of outdoor air supply rate in an office on perceived air quality, Sick Building Syndrome SBS symptoms and productivity. Indoor Air, 10, pp.222-236.

Wargocki, P., Lagercrantz, L., Witterseh, T., Sundell, J., Wyon, D. and Fanger, P. (2002). Subjective perceptions, symptom intensity and performance: a comparison of two independent studies, both changing similarly the pollution load in an office. Indoor Air, 12, pp.74-80.

Wargocki, P. and Wyon, D. (2006). Effects of HVAC on student performance. ASHRAE Journal, 48(10), pp.22-28.

Wargocki, P. and Wyon, D. (2007a). The effects of outdoor air supply rate and supply air filter condition in classrooms on the performance of schoolwork by children: ASHRAE 1257-RP. HVAC\&R Research, 132, pp.165-191.

Wargocki, P. and Wyon, D. (2007b). The effects of moderately raised classroom temperatures and classroom ventilation rate on the performance of schoolwork by children: ASHRAE 1257-RP.

HVAC\&R Research, 132, pp.193-220.

Wargocki, P., Wyon, D., Lynge-Jensen, K. and Bornehag, C. (2008). The effects of electrostatic filtration and supply air filter condition in classrooms on the performance of schoolwork by children: ASHRAE 1257-RP. HVAC\&R Research, 14(3), pp.327-344.

Wyon, D. (1969). The effects of moderate heat stress on the mental performance of children. National Swedish Institute for Building Research, Document D8/69, 83p. Stockholm, Sweden: Building Research Council

Wyon, D. (1970). Studies of children under imposed noise and heat stress. Ergonomics, 13(5), pp. 598-612

Wyon, D. (1974). The effects of moderate heat stress on typewriting performance. Ergonomics, 17, pp.309-318.

Wyon, D. (1979). Human responses to cyclic changes in the thermal environment, Editions INSERM, 75, pp.153-161.

Wyon, D. (1996a). Creative thinking as the dependent variable in six environmental experiments: a review. In: Proceedings of Indoor Air 1996, Nagoya, Tokyo: ISIAQ, 1, pp.419-422 
Wyon, D. (1996b). Individual microclimate control: required range, probable benefits and current feasibility In: Proceedings of Indoor Air 1996, Nagoya. Tokyo, Japan: ISIAQ, 1, pp.1067-1072.

Wyon, D. (1996c). Indoor environmental effects on productivity. In: Proceedings of IAQ'96 Paths to Better Building Environments, Atlanta, USA: ASHRAE, pp.5-15

Wyon, D. (2004). The effects of indoor air quality of performance and productivity. Indoor Air, 14(s7), pp.92-101.

Wyon, D., Andersen, I. and Lundqvist, G. (1979). The effects of moderate heat stress on mental performance. Scandinavian J Work, Environment \& Health, 5,pp.352-361.

Wyon, D., Fanger, P., Olesen, B. and Pedersen, C. (1975). The mental performance of subjects clothed for comfort at two different air temperatures. Ergonomics, 18, pp.359-374.

Wyon, D. and Sandberg, M. (1996). Discomfort due to vertical thermal gradients. Indoor Air, 6, pp. 48-54.

Zhang, X., Wargocki, P. and Lian, Z. (2016a). Physiological responses during exposure to carbon dioxide and bioeffluents at levels typically occurring indoors. Indoor Air, (DOI: 10.1111/ina.12286).

Zhang, X., Wargocki, P., Lian, Z. and Thyregod, C. (2016b). Effects of exposure to carbon dioxide and bioeffluents on perceived air quality, self-assessed acute health symptoms and cognitive performance, Indoor Air, (DOI: 10.1111/ina.12284).

Zhang, X., Wargocki, P. and Lian, Z., (2016c). Human responses to carbon dioxide, a follow-up study at recommended exposure limits in non-industrial environments. Building and Environment, 100, pp.162-171. (DOI: 10.1016/j.buildenv.2016.02.014).

Zhou, X., Lian, Z. and Lan, L. (2014). Experimental study on a bedside personalized ventilation system for improving sleep comfort and quality. Indoor and Built Environment, 23(2), pp.313-323. 